\title{
IMPLEMENTASI TEKNOLOGI IOT (INTERNET OF THINK) PADA RUMAH PINTAR BERBASIS MIKROKONTROLER ESP 8266
}

\author{
Robby Rizky, Zaenal Hakim, Ayu Mira Yunita, Neli Nailul Wardah \\ Fakultas Tehnologi dan Informatika Universitas Matla'ul Anwar Banten \\ Jl Raya Labuan KM 23 Pandeglang Banten \\ robby_bae87@yahoo.com
}

\begin{abstract}
The problem in this study is the difficulty of turning on the lights when we are traveling out of town. When our house looks dark, this can invite evil intentions from thieves. The purpose of this research is to be able to help turn on the lights in every room of the house by long distance. When the homeowner is not in place, every light in the room can turn on and off automatically so that it looks as if there are residents in the house. The tool used in this research is a microcontroller esp 8266. This tool is very simple and has wifi access in it that can support IoT (Internet of Think) technology. The conclusion of this study is that IoT (Internet Of Think) technology is very suitable to be applied because it can cover a very wide area. Even though the homeowner is not in place and this can also be accessed anytime and anywhere which makes it easier for users.
\end{abstract}

Keywords - Internet of Think, smart home, microcontroller, esp 8266

\begin{abstract}
Abstrak - Permasalahan yang ada pada penelitian ini yaitu adanya kesulitan untuk menyalakan lampu ketika kita sedang bepergian keluar kota. Ketika rumah kita terlihat gelap, hal ini dapat mengundang niat jahat dari para pencuri. Tujuan penelitian ini adalah untuk dapat membantu menyalakan lampu di setiap ruangan rumah dengan cara jarak jauh. Ketika pemilik rumah sedang tidak di tempat, maka setiap lampu yang ada di ruangan dapat menyala dan mati secara otomatis sehingga terlihat seolah-olah ada penghuni di dalam rumah. Alat yang digunakan dalam penelitian ini berupa mikrokontroler esp 8266. Alat ini sangat sederhana dan memiliki akses wifi di dalamnya yang dapat mendukung teknologi IoT (Internet of Think). Kesimpulan penelitian ini adalah bahwa teknologi IOT (Internet Of Thnik) sangat sesuai untuk diterapkan karena ini dapat menjangkau area yang sangat luas. Meskipun pemilik rumah tidak berada di tempat dan ini juga dapat diakses kapan pun serta dimana pun yang memudahkan para pengguna.
\end{abstract}

Kata Kunci - Internet of Think,rumah pintar,mikrokontroler,esp 8266

\section{PENDAHULUAN}

Pada era 4.0 segala sesuatu yang di lakukan oleh manusia kebanyakan serba instan dan mudah dalam kemudahan tersebut tidak terlepas dari teknologi yang ada pada saat ini ,teknologi yang di maksud adalah yang sudah tak asing lagi yaitu internet dengan adanya teknologi internet jarak bukan lah masalah di manapun dan kapanpun dapat di lakukan asalkan terkoneksi dengan teknologi internet[1].baru baru ini teknologi internet of think (IOT) melakukan sebuah terobosan baru yaitu memberikan pengontrolan rumah jarak jauh system kendali ini di lakukan untuk mematikan dan menyalakan lampu secara otomatis sehingga penghuni rumah ta usah repot ketika berpegian jauh ketika lampu rumah belum di nyalakan,ketika penghuni rumah sedang berpergian jauh rumah dalam keadaan gelap maka dapat mengundang para pencuri untuk dating kerumah kita.maka dari itu teknologi internet of think menjawab semua itu dengan sistem control rumah cerdas[2].dari penelitian sebelumnya teknologi IOT ini sangat membantu dan sangat efisien di pakai dalam membuat sistem rumah cerdas .rumah cerdas yang di maksud berupa pemantauan dari jarak jauh dan system pengendali nyala lampu otomatis dari jarak jauh dan lain sebagainya [3].penghuni rumah dapat menikmati teknologi yang sangat canggih jika rumah tersebut sudah memiliki teknologi yang sangat mutahir di era 4.0 .pemilik rumah akan di manjakan kecanggihan rumah dengan kecerdasan algoritma yang di tanam di arduino ,teknologi arduino dapat menjadi pintar jika di tanam teknologi kecerdasan buatan yang yang di rancang untuk membuat alat tersebut menjadi cerdas di tambah di padukan dengan teknologi internet yang dapat menjangkau jarak dengan mudah tanpa hambatan jarak dan dimanapun kita berada[4].rumah dapat berfungsi sebagai tempat untuk menikmati kehidupan yang nyaman ,tempat untuk beristirahat tempat untuk berkumpulnya keluarga dan tempat untuk menunjukan tingkat social dalam masyarakat, tetapi terkadang fungsi rumah tersebut tidak dapat terus di rasakan senayaman mungkin hal ini di karnakan banyaknya ke khawatiran ,maka dari itu rumah di buat menjadi rumah pintar agar penghuni rumah tersebut dapat menikmati teknologi yang 
sedang marak pada era 4.0[5].berbagai penelitian menawarkan system kemanan rumah ,keamanan rumah dapat di lakukan dengan pengontrolan cetv jarak jauh dan system password jika akan memasuki ruma.ketika kita akan masuk ke dalam rumah tingkat keamanan yang di tawarkan saat ini banya dengan teknologi cerdas yang memadukan teknologi internet of tihink dengan artificial intelegent maka akan menjadika sebuah teknologi yang sangat mutahir dan sangat dapat di andalkan system cerdas rumah pun dapat mendeteksi gerakan yang sangat mencurigakan dengan memasang sensor sensor yang di terapkan di dalam rumah[6].pada era globalisasi yang semakin berkembang secara pesat berbagai teknologi,semakin banyak perangkat yang sudah dapat mengakses internet, internet of think pun menjadi sebuah bidang penelitian di kalangan penggemar mikrokontroler dan media komunikasi lainya[7].beberapa media pembelajaran saat ini banyak yang menggunakan internet of think di karnakan mengikuti jaman di era globalisasi 4.0 yang serba otomatis dan serba canggih[8][9]. Teknologi mikrokontroler pun banyak di sandingkan dengan teknologi VOIP untuk pengukuran kualitas suara yang di hasilkan di dalam teknologi VOIP[10].dan tehnologi IOT dan mikrokontroleh sering di gunakan pada penelitian untuk pengukuran kualitas udara[11].dan penelitian lainya yang menyandingkan teknologi mikrokontroler untuk pintu otomatis pada rumah pintar[12]. Dan tehnologi buka pintu otomatis bendungan menggunakan teknologi mikrokontroler dan IOT[13].

\section{METODE PENELITIAN}

\section{A. Metodologi pengumpulan data}

Pada penelitian ini,dalam pengumpulandata menerapkan 3metode, yang pertaman metode wawancara,dimana peneliti mengumpulkan data dengan cata bertanya kepada para pakar di bidangnya secara langsung. Metode kedua yang peneliti lakukan adalah melakukan pengamatan secara langsung terhadap objek penelitian, dengan cara melakukan pencatatan secara langsung terhadap kejadian kejadian yang sedang di teliti. Dan metode terakhir adalah studi pustaka pengumpulan data yang di lakukan dengan membacabuku,bukuliterature, jurnal,internet,majalah,d anpenelitian terdahulu yang berkaitan dengan penelitian yang sedang di lakukan.

\section{B. Metode Analisis Data}

Metode Analisis data yang peneliti lakukan adalah menganalisa data tentang keluhan para pemilik rumah ketika rumah sering di tinggalkan dan ke hawatiran yang sangat besar ketika para pemilik rumah enggan meninggalkan rumah jarak jauh di karnakan rumah gelap dan tidak ada yang menyalakan lampu indicator mengundang para maling dating kerumah tersebut agar kedepanya data tersebut dapat di aplikasikan ke dalam sebuah alat IOT yang dapat di gunakan sebagaimana mestinya.

\section{Tahapan Penelitian}

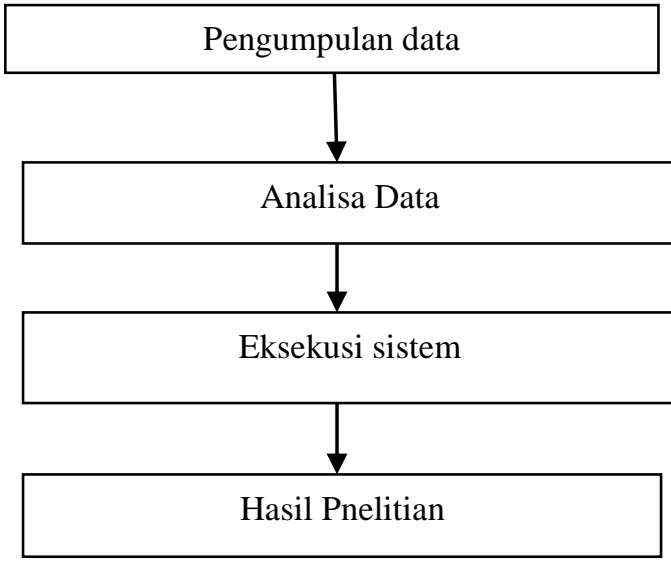

Gambar I Tahapan Penelitian Sumber :(Hasil Penelitian 2018)

Keterangan :

1. Pengambilan data di proses dari wawancara dan daftar pertanyaa kuesioner untuk mengumpulkan fakta tentang sistem kebutuhan dan pilihan.

2. Analisa data :analisa data dalam penelitian ini adalah suatu kegiatan yag di lakukan untuk mengubah data hasil penelitian menjadi sebuah informasi yang dapat di gunakan dalam sebuah kesimpulan data.

3. Eksekusi sistem : tahapan ini adalah tahapan bagaimana alat tersebut dapat berjalan sebagaimana mestinya sesuai yang di inginkan .

4. Hasil penelitian merupakan hasil yang nantinya di harapkan dalam penelitian ini.

\section{HASIL DAN PEMBAHASAN}

Tehnologi internet of thing sudah di gunakan dalam beberapa hal salah satunya adalah dalam penelitian ini yang membuat rumah pintar menyalakan dan mematikan lampu secara otomatis tanpa halangan jarak dan waktu kapan pun itu.

Teknologi yang di gunakan yaitu handpone alat mikrokontroler ESP8266 dan koneksi internet itu sendiri database yang di gunakan yaitu thinkspeak yang dapat menyipan data ketika perekaman suara berjalan penelitian ini sangat sederhana dan sangat bermanfaat bagi kalangan yang sering berpergian keluar kota. 
Langkah langkah ketika pengambilan data sampai output hasil

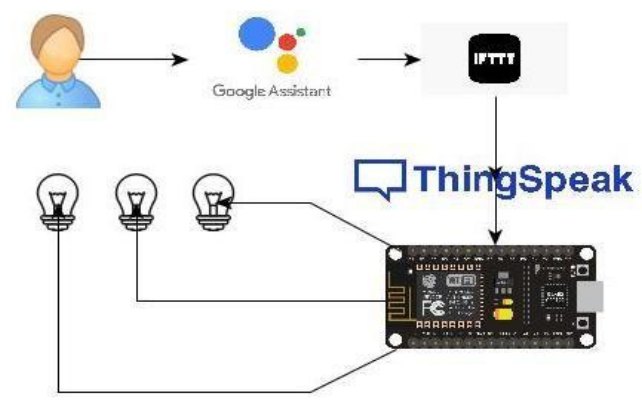

Gambar1 desain input

Keterangan : dari user menginput assistant dan iftt merubah bahasa yang di input google assistant ke bahasa mesin agar di mengerti oleh mikrokontroler.kemudia relay menerima perintah dari mikrokontroler untuk menyalakan dan mematikan lampu, relay tidak akan berfungsi jika tidak ada perintah dari mikrokontroler .

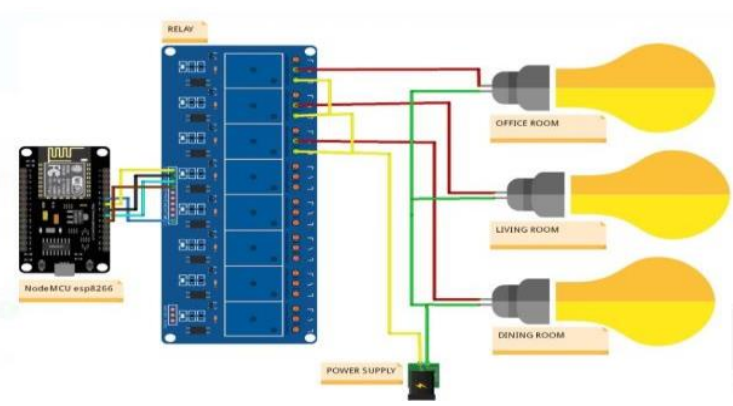

Gambar 2 desain output

Keterangan : pada bagian teori telah di jelaskan bahwa google assistant akan memproses kata-kata yang di ucapkan dan IFTTT akan mengubahnya menjadi perintah yang di mengerti oleh mesin dan di kirim ke Thingspeak Berikut adalah pseudocode dari system yang di buat untuk logika system dari google

assistant ke IFTTT dan dari IFTTT ke Thingspeak dan dari logika operasi Thingspeak ke arduino melalui NODEMCU ESP8266 ke perangkat rumah lampu yang di hubungkan relay.ketika relay aktif maka aliran listrik mengalir dan lampu akan menyala ketika relay mati maka tidak ada aliran listri maka lapu pun akan matiproses ini memerlukan teknologi internet yang menghubungkan antara modul erduino esp 8266 dengan database dan lainnya
Implementasi system

Beberapa hasil telah di dapat melaluipenelitian ini.beberapa hal ini seperti menyalakan dan mematikan lampu dengan voice command telah berhasil di lakukan dengan google assistant.

Tabel 1 Hasil Percobaan Mengenali Perintah

\begin{tabular}{|l|l|l|l|l|}
\hline No & Lampu & $\begin{array}{l}\text { WaktuMen } \\
\text { yala }\end{array}$ & $\begin{array}{l}\text { Waktu } \\
\text { Padam }\end{array}$ & gan \\
\hline 1 & Lampu 1 & $17: 11: 02$ & $17: 11: 04$ & Sesuai \\
\hline 2 & Lampu 2 & $17: 12: 02$ & $17: 12: 04$ & Sesuai \\
\hline 3 & Lampu 3 & $17: 13: 02$ & $17: 13: 04$ & Sesuai \\
\hline
\end{tabular}

Tabel 2 Pengujian Prototipe Rumah

\begin{tabular}{|l|l|l|l|}
\hline NO & Lampu & Kondisi & Keterangan \\
\hline 1 & Lampu 1 & On & Sesuai \\
\hline 2 & Lampu 1 & Off & Sesuai \\
\hline 3 & Lampu 2 & On & Sesuai \\
\hline 4 & Lampu 2 & Off & Sesuai \\
\hline 5 & Lampu 3 & On & Sesuai \\
\hline 6 & Lampu 3 & Off & Sesuai \\
\hline
\end{tabular}

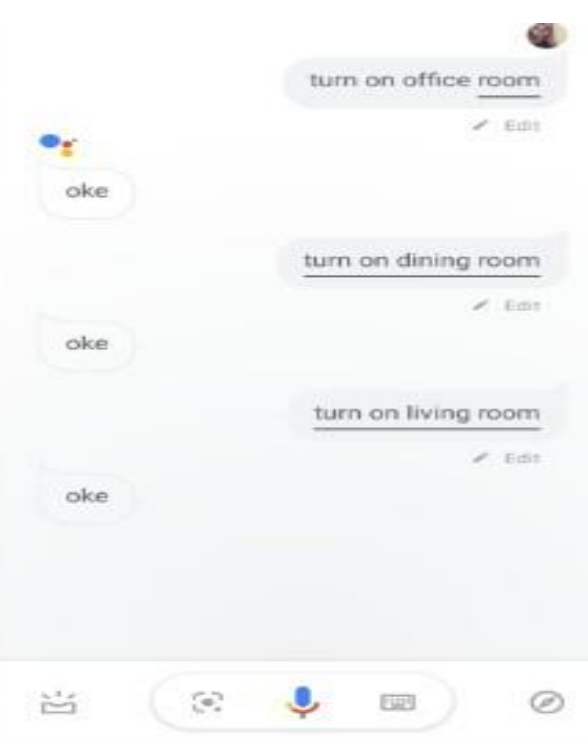

Gambar 3 uji coba pemanggilan dengan voice 
Gambar di atas menunjukan ketika perekaman suara ke google assistance berjalan.

Keterangan : gambar di atas menunjukan ketika pemanggilan office room on atau dining room on berhasil maka indicator akan menunjukan angka 1 .

\section{KESIMPULAN}

Berdasarkan penelitian ini teknologi IOT sangat bermanfaat dalam membuat rumah pintar tersebut dikarnakan teknologi internet dapat di akses di mana pun dan kapanpun jika kita ingin mengaksesnya.dengan teknologi IOT ini menjawab semua permasalahan yang ada dan memberikan solusi bagi seseorang yang gemar berpergian jauh keluar kota dan kita merasa hawatir jika rumah kita belum ada yang menyalakan lampu.penelitian ini masih dapat di kembangkan dengan cara menambahkan teknologi CCTV pada setiap ruangan dan kita dapat memantau keadaan rumah dengan cara memonitoring dari kejauhan dengan teknologi internet.

\section{DAFTAR PUSTAKA}

[1] B. Artono and F. Susanto, "Wireless Smart Home System Menggunakan Internet Of Things," J. Teknol. Inf. dan Terap., vol. 5, no. 1, pp. 17-24, 2019, doi: 10.25047/jtit.v5i1.74.

[2] F. Z. Rachman, "Smart Home Berbasis Iot," Snitt, pp. 369-374, 2017, [Online]. Available: http://jurnal.poltekba.ac.id/index.php/prosiding /article/view/423.

[3] M. Muharam, M. Latif, and M. Saputra, "Sistem Kendali Jarak Jauh Berbasis Web untuk Sistem Rumah Pintar," J. Nas. Tek. Elektro, vol. 7, no. 3, p. 203, 2018, doi: 10.25077/jnte.v7n3.502.2018.

[4] I. M. A. Wirawan, G. S. Santyadiputra, and N. Sugihartini, "Sistem Pemantau Suhu Lab Jarak Jauh Berbasis Arduino," Denpasar-Bali, 28 Oktober 2017, pp. 82-89, 2017.

[5] Ruuhwan, R. Rizal, and I. Karyana, "Innovation in Research of Informatics ( INNOVATICS ) Sistem Kendali dan Monitoring pada Smart Home Berbasis Internet of Things ( IoT )," vol. 2, pp. 43-50, 2019.

[6] M. I. KURNIAWAN, U. SUNARYA, and R. TULLOH, "Internet of Things: Sistem Keamanan Rumah berbasis Raspberry Pi dan Telegram Messenger," ELKOMIKA J. Tek. Energi Elektr. Tek. Telekomun. Tek. Elektron., vol. 6, no. 1, p. 1, 2018, doi: 10.26760/elkomika.v6i1.1.

[7] H. Isyanto and A. Nandiwardhana,
"Perancangan DC Cooler Berbasis Internet of Things," Resist. (elektRonika kEndali Telekomun. tenaga List. kOmputeR), vol. 2, no. 2, p. 95, 2019, doi: 10.24853/resistor.2.2.95-104.

[8] M. ARI AFRIZAL, "Rancang Bangun Rumah Pintar Berbasis Iot (Internet of Things) Sebagai Media Pembelajaran Pada Mata Pelajaran Pemrograman, Mikroprosesor, Dan Mikrokontroller Di Smkn2 Surabaya," J. Pendidik. Tek. Elektro, vol. 7, no. 1, pp. 7986, 2017.

[9] P. Studi, T. Komputer, and S. Vokasi, "SEDERHANA BERBASIS IOT DI INTERACTIVE ROBOTICS," 2019.

[10] R. Rizky and Z. Hakim, "Analysis and Design of Voip Server (Voice Internet Protocol) using Asterisk in Statistics and Statistical Informatics Communication of Banten Province using Ppdioo Method," J. Phys. Conf. Ser., vol. 1179, p. 012160, 2019, doi: 10.1088/1742-6596/1179/1/012160.

[11] J. Prayudha, A. Pranata, and A. Al Hafiz, "Implementasi Metode Fuzzy Logic Untuk Sistem Pengukuran Kualitas Udara Di Kota Medan Berbasis Internet of Things (Iot)," Jurteksi, vol. 4, no. 2, pp. 141-148, 2018, doi: 10.33330/jurteksi.v4i2.57.

[12] R. Rizky, T. Hidayat, A. Hardianto, and Z. Hakim, "Penerapa Metode Fuzzy Sugeno Untuk pengukuran Keakuratan Jarak Pada Pintu Otomatis di CV Bejo Perkasa," vol. 05, pp. 33-42, 2020.

[13] A. M. Yunita, N. N. Wardah, A. Sugiarto, E. Susanti, L. Sujai, and R. Rizky, "Water level measurements at the cikupa pandeglang bantendam using fuzzy sugenowith microcontroler-based ultrasonik sensor," $J$. Phys. Conf. Ser., vol. 1477, no. 5, 2020, doi: $10.1088 / 1742-6596 / 1477 / 5 / 052048$. 